\title{
Los Pronombres: La Importancia De Nuestro Idioma Diario
}

\author{
Amy Greene ${ }^{1}$ a, Benjamin M Sullivan ${ }^{2}$ \\ ${ }^{1}$ Washington County School District, ${ }^{2}$ Translator, Dixie State University \\ Keywords: los pronombres de inglés, gramática inglesa, uso del pronombre, thou, inglés medieval, gramática, pronombres \\ https://doi.org/10.36898/001c.21507
}

\section{Curiosity: Interdisciplinary Journal of Research and Innovation}

Vol. 2, 2021

\begin{abstract}
Tenemos el idioma para crear y mantener relaciones. Entonces, es natural que el idioma nos ofrezca pistas sobre la conexión entre las personas a nuestro alrededor y el estatus social. Los pronombres se emplean más que otras palabras para explicar relaciones. Durante el período del inglés medieval se usaron los pronombres "you" (usted) y "thou" (tú) cuando una persona se dirigía a gente de distintas clases sociales. "You" fue empleado por los miembros de la clase alta cuando se dirigían al uno al otro y por los miembros de la clase baja cuando se dirigían a gente superior. "Thou" fue empleado por los miembros de la clase baja cuando se dirigían al uno al otro, a familiares íntimos, y cuando rezaban a Dios. Estas distinciones permanecen durante el principio del periodo del inglés moderno y las vemos en las obras de Shakespeare. Investigué los pronombres "you" y "thou" en Otelo de Shakespeare al buscar cada incidencia de aquellos pronombres que empleaban los personajes de Otelo, Desdémona, Yago, y Emilia. Resultó evidente que Shakespeare usó los pronombres tradicionalmente hasta llegar a momentos de gran ira o al final de la obra. El inglés moderno ha dejado de usar el pronombre "thou", pero todavía usamos los pronombres para indicar el estatus social. Según James W. Pennebaker, la gente de un estatus social más bajo suele usar demasiado el pronombre " $P$ " (yo). La gente de un estatus social más alto usa los pronombres "we" (nosotros) y "you" más a menudo. Investigo el uso de los pronombres en la obra de teatro Trifles (Nimiedades) de Susan Glaspell. Establezco unas conclusiones acerca de la correlación entre los pronombres y el estatus social durante el inicio del inglés moderno y el periodo del inglés moderno por medio de una comparación entre Otelo y Trifles. Las investigaciones que hago muestran que las relaciones humanas siguen iguales aunque cambia el lenguaje que se emplean, y que el estudio de los pronombres nos ayuda a entender esas relaciones mejor a través del análisis literario.
\end{abstract}

El inglés es un idioma que siempre está evolucionando, lo cual permite flexibilidad en las reglas. Con ejemplos desde el himno de Caedmon, hasta Shakespeare, y Twitter, cada nueva época y autor incluye sus propias técnicas en sus escritos. Debido a estas habilidades de flexibilidad y cambio, los lectores tienen la oportunidad de estudiar y comprender la manera en que las personas han escrito, y seguirán escribiendo, a lo largo de la historia. Uno de los cambios que los lectores pueden estudiar en el idioma inglés es el uso de los pronombres y como estos revelan un fondo adicional en los textos literarios a lo largo del tiempo.

\footnotetext{
a Amy Greene se graduó de la universidad de Dixie State en 2019. Ella fue la presidenta de Sigma Tau Delta, una sociedad nacional para estudiantes de honor en el idioma inglés, también fue editora para el periódico literario, The Southern Quill, y ha hablado en varias conferencias dentro de los EE.UU. Actualmente, ella es maestra de arte literario en Washington Fields Intermediate y le gusta ayudar a sus estudiantes a desarrollar habilidades escritas ya reconocer que aman la lectura más de lo que pensaron. Vive con su marido en Hurricane, Utah.
} 
El “you” (usted) formal y el "thou” (tú) informal desde el inglés medieval hasta el principio del inglés moderno sirven como ejemplos. La distinción entre los dos pronombres, a través del análisis literario, permite que los lectores ganen una mejor percepción sobre la relación entre los personajes en un diálogo al introducir un nuevo nivel de tonalidad. El estudio de los pronombres puede tener beneficios prácticos, tal como aprender el pronombre preferido de una persona o estudiar las relaciones entre los personajes en una variedad de textos. Cuando analizamos los usos formales e informales de esas palabras en Otelo de Shakespeare, la escritura revela con más detalle las personalidades y relaciones de Otelo, Yago, y Desdémona, y sugiere cómo esas relaciones se desarrollan a lo largo de la obra. Este concepto también se aplica a la literatura moderna tal como se ve en Trifles (Nimiedades) por Susan Glaspell. A lo largo del análisis los lectores pueden descubrir una comprensión más profunda de la obra y las relaciones entre cada personaje; no solo por medio del estudio de los pronombres, sino también por medio de otros matices modernos que se encuentran en el idioma.

Los pronombres siempre han tenido un impacto en el idioma inglés, en particular la manera que muestran la naturaleza de las relaciones interpersonales. La meta es descubrir el significado más profundo de lo que parece ser un lenguaje sin importancia entre los anglohablantes hoy en día. Por medio de las investigaciones académicas acerca de los pronombres y la tonalidad del lenguaje que se usa en la vida diaria, nuevos significados se añaden a las palabras que emplean los lectores y personajes. También, al examinar los datos de la frecuencia del uso de los pronombres en ambas obras, entenderemos mejor los personajes de cada obra.

Aunque el inglés tiene muchas normas y regulaciones en nuestro tiempo moderno, no siempre ha sido así. Según Seth Lerer (2007), un distinguido profesor de inglés de la universidad de San Diego, California y el autor de Inventing English: A Portable History of the Language (Inglés inventado: una historia portátil del idioma ${ }^{1}$ ), no fue hasta la mitad del siglo XVI cuando el estilo cancillería llegó a ser el estilo más extendido y aceptado como sistema fijado para llegar a una uniformidad en la lengua inglesa (p. 115). Debido a que el inglés no tenía un estándar fijo durante la mayor parte de su existencia, los autores tuvieron la opción de crear una interpretación propia del idioma por medio de sus obras. Lerer reconoce que Geoffrey Chaucer, quien es considerado el padre de la literatura inglesa por muchos, es un autor muy conocido que usa esta falta de uniformidad para aumentar su escritura en el siglo XIV (p. 70).

Un aspecto de la escritura de Chaucer que lo separa de los otros escritores del siglo XIV es su uso del "idioma común". En este punto de la historia, lo escrito no siempre reflejaba la manera que la persona común hablaba. La obra más popular de Chaucer, The Canterbury Tales (Los cuentos de Canterbury), 
incluyó un estilo de escritura diferente dependiendo de cuál personaje habló y con quien interactuó aquel personaje. En la colección de cuentos, vemos un ejemplo de la dualidad de los pronombres singulares: el uso de "you" formal y de "thou" informal. Vemos esto en particular en el General Prologue (Prólogo general) cuando usa Chaucer diferentes pronombres dependiendo del personaje que está hablando, y con cuál personaje interactúa. El inglés medieval hace una distinción entre los pronombres personales para mostrar las relaciones personales, la intimidad, la edad, y el estatus de las personas involucradas en la conversación (p. 76).

"You" es la manera formal para dirigirse a alguien y se lo usa para mostrar respeto e igualdad en una relación. Se emplea "thou" entre familiares cercanos y por personas de la clase baja cuando se hablan entre sí, o por personas de un estatus alto cuando se dirigen a personas de un estatus bajo.

Raychel Reiff (2010), la autora de "Choosing Thou or You to Reveal Ideal Relationships in 'The Knight's Tale" (Escoger entre tú y usted para revelar las relaciones ideales en 'El cuento del caballero's) dice que las personas también emplean "thou" para dirigirse a Dios en oración, lo cual muestra una relación personal con un ser superior (p. 70).

Tal como hemos visto en la obra de Chaucer, el estudio de la manera en la que los pronombres funcionan en un texto con una percepción más contemporánea es importante porque los pronombres personales no suelen cambiar, y cuando evolucionan es un cambio significativo para el inglés. La eliminación del uso antiguo de "thou” en inglés moderno no es la única ocasión que los pronombres personales han metamorfoseado. Empezamos a ver un cambio en la aceptación del pronombre singular de "they" (ellos) en años recientes. John McWhorter (2018), profesor de la lengua inglesa de la universidad de Columbia, Nueva York y editor contribuyente de The Atlantic, escribe en su artículo "Call Them What They Wants" (Llámalos lo que ellos quiera $^{3}$ ) que aunque el cambio sea difícil, los estudiantes que prefieren "they" como su pronombre preferido aumenta cada año. Pilkington (2019, p. 73) discute acerca del uso de "they" como pronombre singular es muy aceptado por lingüistas, e incluso el editor de The Washington Post ha cambiado las directrices para aceptar los pronombres sin géneros específicos en los periódicos. El enfoque en los cambios en el uso de los pronombres personales no solo tiene un uso práctico, tal como los pronombres preferidos y las directrices de los periódicos, sino produce resultados en el campo del análisis literario de Shakespeare. Shakespeare sabía el poder de los pronombres, y los usaba para mejorar la narrativa en sus obras escritas. Sabía la forma clásica de los pronombres personales usados por sus predecesores como Chaucer, y hay evidencia de que Shakespeare usaba los pronombres personales "you" formal y "thou" informal en la misma manera (Lerer, 2007, p. 131). Al examinar los usos 
Tabla A, Otelo, 8,284 palabras en total, todas las interacciones entre Otelo, Desdémona, Yago y Emilia.

\begin{tabular}{|l|r|r|r|r|r|}
\hline & Otelo & Yago & Desdémona & Emilia & Total \\
\hline You (Usted) & 29 & 49 & 23 & 60 & 161 \\
\hline Thou (Tú) & 60 & 2 & 4 & 16 & 82 \\
\hline We(Nosotros) & 16 & 4 & & 21 & 41 \\
\hline$I$ (Yo) & 75 & 51 & 115 & 47 & 261 \\
\hline Total & 180 & 106 & & 144 & 545 \\
\hline
\end{tabular}

de los pronombres formales e informales en Otelo, nosotros como lectores y personas que asisten las obras empezamos a comprender más profundamente cómo las relaciones entre Otelo y Yago, el villano, y entre Otelo y Desdémona, su mujer, se desarrollan en la obra (Tabla A).

La primera relación que examinaré es la de Otelo y Yago. Es obvio que desde el principio de la obra Yago se aprovecha de la confianza que Otelo tiene en él al manipular lo que Otelo piensa acerca de su esposa. Yago intenta separar a Otelo y su nueva esposa al crear una mentira detallada que Desdémona ha sido infiel a Otelo con Casio. A pesar del subterfugio de Yago, las interacciones entre Otelo y este siguen las reglas adecuadas del uso de "you" y "thou" (Shakespeare, 2016, 3.3). Debido a que Otelo tiene una clase social más alta que Yago, Yago siempre lo dirige con el pronombre formal de "you". Mientras que está simultáneamente respetando a Otelo y guardando su confianza, Yago se dirige a Otelo adecuadamente. "Gran señor," dice Yago, "usted sabe que lo quiero." Entonces responde Otelo, "Pienso que sí me quieres. Debido a que sé que estás lleno de amor y honestidad, y piensas en tus palabras antes de decirlas" (Shakespeare, 2016, 3.3.129-132). Aquí parece que haya un respeto de parte de Yago hacia Otelo por medio del uso del pronombre formal "you", lo cual permite que Yago manipule Otelo a lo largo de la obra. Esto es algo que no está fuera de lo normal para Yago, y los lectores ven esto debido a que él manipula otros personajes en la obra, como cuando usa "you" para dirigirse a Rodrigo. Cuando su relación se establece y Yago intenta aumentar la confianza de Rodrigo, Yago lo dirige como un amigo cercano, al usar "thou" para representar este cambio. Cuando Yago intenta convencer a Rodrigo del affaire entre Desdémona y Casio, Yago le pregunta, “¿No la viste jugar con la palma de su mano?” (Shakespeare, 2016, 2.1.243).

La próxima relación que veremos en esta obra en cuanto al uso de los pronombres es la de Otelo y Desdémona. Los dos se casan y el discurso entre ellos está lleno de un respeto mutuo a lo largo de la obra. Entre cada interacción entre los dos, "you" es el pronombre que se emplean tal como algunos términos de cariño como "dulce". Según los autores Roger Brown y Albert Gilman (1989) en "Politeness Theory and Shakespeare's Four Major Tragedies"(La teoría de la cortesía y las cuatro tragedias mayores de Shakespeare ${ }^{4}$ ), "los hablantes de la clase alta dijeron "you" a los unos a los otros;... En las tragedias [de 
Shakespeare], las díadas del intercambio de "you" incluía a los esposos" (p. 177). Vemos este respeto a lo largo de la primera mitad de la obra, y pasa por un cambio drástico en la última mitad de la obra.

Ya que empiezan a ver los lectores el deterioro de su relación en el Acto 4, Escena 2 cuando Otelo está fastidiando a Desdémona acerca de su presunto affaire con Casio. Desdémona está confundida por las palabras atacantes de Otelo y le dice que ella no le entiende. Él responde con, “¿Por qué? ¿Qué eres?” y responde Desdémona, "Su mujer, gran Señor, su verdadera y fiel esposa" (Shakespeare, 2016, 4.2.36-38). Otelo continúa durante la escena refiriéndose a Desdémona como una "ramera" (Shakespeare, 2016, 4.2.84) pero la habla con el uso de "you" en la misma oración. Seth Lerer (2007) sugiere que muchas veces el pronombre "thou" puede ser empleado en un momento de gran ira (p. 108), tal como el momento citado entre Otelo y Desdémona. Después de aquel momento de gran ira, Otelo se dirige a Desdémona de nuevo empleando "you" por la duración de la escena. El uso del pronombre cambia de nuevo al final de la obra justo antes de que Otelo mata a Desdémona. En Acto 5, Otelo pide a Desdémona que confiese todos sus pecados. Otelo la pide a pensar en sus pecados y ella responde, "Son los amores que le doy a usted." Entonces la dice Otelo, "Ay, y por eso mueres" (Shakespeare, 2016, 5.2.43-44). Esta amenaza es cuando el cambio en su relación es permanente. Es importante notar que Desdémona jamás se dirige a Otelo con el uso de "thou" en la obra, lo cual sugiere que Desdémona siempre muestra respeto y devoción a su marido.

Vemos otro personaje, Emilia, cambiar la manera en que emplea "you" y "thou" durante la obra. Su cambio viene al final de la obra cuando entra y ve a Otelo intentando matar a Desdémona y empieza ella a usar "thou" cuando se dirige a Otelo. Cada personaje hasta este punto en la obra se ha dirigido a Otelo usando "you" por respeto o superioridad. Aquí Emilia se dirige a Otelo como "el diablo más negro," y a Desdémona como "la angelita" (Shakespeare, 2016, 5.2.134-135). Después de este comentario, Emilia se dirige a Otelo usando el pronombre "thou" hasta que muere Otelo. Emilia dice, "La defraudaste, y eres un diablo" (Shakespeare, 2016, 5.2.137). Brown y Gilman (1989), "La ira y el desdén son las emociones que causan los cambios más obvios" (p. 117). El cambio en el uso de los pronombres "you" y "thou" por Emilia se lleva a cabo por la ira que siente acerca del asesinato de Desdémona por mano de Otelo.

$\mathrm{Al}$ analizar el uso de "you" y "thou" en las obras de Shakespeare, sacamos a la luz un nivel más profundo de significado, el cual aumenta las historias que leemos. En Otelo, descubrimos cuán complejos son los personajes de Otelo, Yago, Desdémona, y Emilia por medio de la manera en que se dirigen los unos a los otros y cómo esta manera cambia a lo largo de la obra. Al notar el uso de los pronombres en la literatura, moderna o histórica, nos ayuda percibir el texto de una manera más profunda. Debido a que el inglés ha cambiado drásticamente desde su forma más antigua, y todavía cambia para adaptarse a nuestro mundo moderno, los pronombres seguirán adquiriendo tonalidades y significados nuevos, y como hablantes de este idioma, hay que aprender a adaptarse a estos tipos de cambios. 
A medida que la lengua inglesa evoluciona, se pierde la distinción entre "you" y "thou". En nuestro mundo moderno tenemos que mirar a otras partes del diálogo para ayudar a las personas a entender relaciones escritas y las de la vida real. Los lectores pueden ver un ejemplo de esto en la obra pequeña Trifles (Nimiedades) por Susan Glaspell. Trifles se estrenó en el teatro Wharf en Massachusetts en el año 1916. La obra tiene lugar en la cocina del señor y señora Wright en una casa de labranza el día después que se halló al señor Wright muerto en su habitación. Los cinco personajes, George Henderson (el abogado del condado), el señor y la señora Henry Peters (el sheriff local y su mujer) y el señor y la señora Lewis Hale (los vecinos de los Wrights) están en la casa para encontrar evidencia para averiguar quién mató al señor Wright.

Los lectores empiezan la lectura con una introducción a los cinco personajes. Hay tres personajes que son hombres y se identifican por su nombre completo o su profesión. Hay dos personajes que son mujeres y se identifican por "Señora" y el apellido de su marido. En "Feminism and Marriage: To Be or Not to Be Mrs B" (El feminismo y el matrimonio: ser o no ser señora Tal'5), los autores Precilla Y. L. Choi y Steve Bird (2003) discuten que muchas veces se ve al matrimonio como un beneficio económico o una necesidad religiosa. El matrimonio es una unión que abarca muchas connotaciones acerca de qué hará la mujer y cómo se comportará. Esto incluye, en la cultura inglesa, que las mujeres se sienten obligadas, y la gente espera, que adquieran el apellido de su marido. Esta "regla obligatoria" puede conducir a que muchas mujeres lleguen a ser "Señora-adjuntada-a-alguien" (p. 449). Debido al estudio de los nombres de cada personaje, los lectores pueden usarlos como otra fuente para entender las relaciones entre los personajes.

Vemos esta idea con los personajes del sheriff, Henry Peters y su esposa, la señora Peters. Nunca nos enteramos del primer nombre de la esposa, y muchas veces los hombres en la obra la desprecian, aun su marido. Los lectores reconocen las expectativas sociales que se ponen sobre la señora Peters a lo largo de la obra. Por ejemplo, ella se siente obligada a apoyar a su marido, a pesar de la forma en que la trata. Al principio de la obra las mujeres encuentran una manta en la que la señora Wright trabajaba, y la señora Peters pregunta si la señora Wright la iba a acolchar o anudar. Entonces el señor Peters dice, "iSe preguntan si la iba a acolchar o anudar!” (Glaspell, 2013, p. 748), riéndose de la idea de que se preocupen las mujeres de cosas tan banales.

Otro ejemplo es cuando los personajes hablan acerca de los artículos que la señora Peters llevará a la señora Wright y si deben investigarlos. Dice el abogado del condado, "Bueno, supongo que no son peligrosas las cosas que han elegido las chicas. No. La señora Peters no necesita supervisión. Por cierto, la esposa del sheriff está casada a la ley" (Glaspell, 2013, p. 752). Para los hombres de la obra, es obvio que una mujer jamás haría algo que su marido no querría que haga, pero en esta situación, la señora Peters guarda la evidencia que tiene en secreto. 
Tabla B. Trifles: 5113 palabras en total, el texto completo.

\begin{tabular}{|c|r|r|r|r|r|r|}
\hline & $\begin{array}{l}\text { Abogado del } \\
\text { Condado }\end{array}$ & \multicolumn{2}{|l|}{$\begin{array}{l}\text { Señor Hale (el } \\
\text { Sheriff) }\end{array}$} & $\begin{array}{l}\text { Señora } \\
\text { Hale }\end{array}$ & $\begin{array}{l}\text { Señor } \\
\text { Peters }\end{array}$ & $\begin{array}{l}\text { Señora } \\
\text { Peters }\end{array}$ \\
\hline we & 4 & 10 & 5 & & 5 & 24 \\
\hline you & 16 & 17 & 18 & & 9 & 60 \\
\hline I & 13 & 58 & 48 & & 20 & 139 \\
\hline Total & 33 & 85 & 71 & & 34 & 225 \\
\hline
\end{tabular}

A pesar de la eliminación de "you” y "thou” en el idioma moderno del inglés, los lectores todavía pueden estudiar los pronombres personales para entender los personajes y sus relaciones.

Según Maia Alavidze (2017), la autora de "The Use of Pronouns in Political Discourse" (El uso de los pronombres en el discurso political ${ }^{6}$ ), el pronombre personal de "we" puede emplearse para "compartir responsabilidad, y crear participación con el público” (p. 351) y los lectores ven varios personajes que usan "we" para demostrar una conexión durante Trifles. Por ejemplo, lectores ven esto con el abogado del condado, el hombre que supervisa la investigación del asesinato del señor Wright, George Henderson. Henderson usa la palabra " $w e$ " cuando pide ayuda de los señores Hale y Peters a la hora de buscar evidencia, dice, "Bueno, primero vayamos al piso de arriba, y después fuera al granero y alrededor de él," (Glaspell, 2013, p. 745). Cuando los hombres van a buscar evidencia al final de la obra cuando Henderson quiere continuar la búsqueda dice él que no está satisfecho que "nosotros (los hombres) no podemos hacer un mejor trabajo" (Glaspell, 2013, p. 752). Henderson emplea "we" como una manera para dar a conocer a los hombres que aprecia su ayuda en la investigación y que necesitan seguir en su intento.

Solo se emplea la palabra " $w e$ " cuando se dirigen personas del mismo género. Como vemos en Tabla $\mathrm{B}$, se emplea "we" diecinueve veces por los hombres y sólo cinco veces por la señora Peters cuando se dirige a la señora Hale. Los lectores ven que el señor Hales usa el pronombre "we" varias veces cuando da una descripción del crimen a Henderson. Usa "we" cuando se refiere a Harry, el hombre que estuvo con él cuando llegó por primera vez a la casa de los Wright. Cuando el señor Hale pregunta acerca de cómo puede ser que la señora Wright no se despertó cuando mataron al señor Wright, él dice, "Debemos de habernos parecido confundidos por no saber cómo pudo haber ocurrido esto.” A lo cual responde la señora Wright, "Duermo profundamente" (Glaspell, 2013, p. 745). Tales maneras exclusivas de usar "we" dentro de personas del mismo género implica que el personaje siente afinidad y crea alianzas con grupos del mismo género y no alcance fuera de aquellos límites.

Cuando personas del género opuesto se dirigen, emplean el pronombre "you". El estudio de este pronombre en Trifles nos permite examinar las relaciones románticas del principio del siglo XX. En Otelo vemos que los 
personajes que son de géneros opuestos respetan los unos a los otros y siguen directrices convencionales, con excepción del final de la obra cuando una tragedia ocurrió. Otelo y Desdémona se dirigen el uno a la otra con el uso de "you" a lo largo de la obra, lo cual muestra respeto en su relación. En Trifles, los lectores observan una carencia de respeto en cada relación entre hombre y mujer, aunque los personajes usan "you", lo cual en este punto ha perdido sus significados adicionales de indicar una diferencia.

En el tiempo de Shakespeare, el pronombre "you" se empleaba como signo de respeto, pero en el día moderno "you" se emplea para crear distanciamiento (Alavidze, 2017, p. 351). Según J. W. Pennebaker, “we” "you” son empleados por personas de poder. Los lectores ven el uso de este pronombre por el abogado del condado cuando la señora Hale comenta acerca de la suciedad de la cocina de la señora Wright cuando dice él, "Ay, veo que usted es fiel a su sexo. Sin embargo, usted y la señora Wright eran vecinas. Supongo que eran amigas también" (Glaspell, 2013, p. 746). El propósito de este comentario no solo fue menospreciar a la señora Hale, sino tratar la carencia de amistad entre ella y la señora Wright. El abogado del condado también critica a la señora Wright aún más al decir que no nació con "los instintos caseros" (Glaspell, 2013, p. 746). "You” es el segundo más usado pronombre en Trifles, lo cual muestra una separación entre cada uno de los géneros (Tabla B $)$.

Esta obra toma lugar en una comunidad que se siente aislada con los habitantes de la misma, y lo vemos por medio de las muchas veces que usan " $I$ " durante la obra (Pennebaker, 2013). El marido que fue asesinado y su esposa viven $\tan$ lejos del pueblo que casi nadie les hablaba. Entonces, nadie sabía que había algo malo en su relación. Este hecho plaga a las mujeres con culpa, y la señora Hale dice, "¡Ay, ojalá que yo les hubiese visitado de vez en cuando! ¡Eso era un crimen! (Glaspell, 2013, p. 751). Tabla B muestra a los lectores que " $I$ " fue el pronombre más empleado en la obra, con el total llegando a 139 veces, lo cual hace un énfasis de la desconexión en esta comunidad.

Si los examinamos con propósito, los pronombres y otros detalles de nuestro idioma pueden ser importantes e informativos. Desde la concepción del idioma, el inglés ha sido permitido trastornar las reglas. Por medio del estudio de la manera que el idioma cambia, y lo que significa cada cambio, los lectores pueden comprender lo que leen en un nivel más profundo. Este cambio en el significado es importante para los pronombres. Los pronombres pueden informar a los lectores de mucho, desde cómo es una relación entre dos personas hasta el pronombre que una persona prefiere. Al enfocarse en los pronombres y otros aspectos del idioma en la literatura, tal como en Otelo por Shakespeare y Trifles por Susan Glaspell, los lectores ganan una mejor percepción en cuanto a los personajes y a la misma vez experimentan las tonalidades del idioma inglés. 
This is an open-access article distributed under the terms of the Creative Commons Attribution 4.0 International License (CCBY-SA-4.0). View this license's legal deed at https://creativecommons.org/ licenses/by-sa/4.0 and legal code at https://creativecommons.org/licenses/by-sa/4.0/legalcode for more information. 


\section{References}

Alavidze, M. (2017). The Use of Pronouns in Political Discourse. International Journal of Arts $\varepsilon^{\circ}$ Sciences, 9(4), 349-355.

Brown, R., \& Gilman, A. (1989). Politeness theory and Shakespeare's four major tragedies. Language in Society, 18(2), 159-212. https://doi.org/10.1017/s0047404500013464

Choi, P. Y. L., \& Bird, S. (2003). VI. Feminism and Marriage: To be or not to be Mrs B. Feminism Eo Psychology, 13(4), 448-453. https://doi.org/10.1177/09593535030134008

Glaspell, S. (2013). Trifles (N. Baym \& R. S. Levine, Eds.; 8th ed.). W. W. Norton \& Company.

Lerer, S. (2007). Inventing English: A portable history of the language. Columbia University Press. https://doi.org/10.7312/lere13794

McWhorter, J. (2018). Call Them What They Wants. The Atlantic. https://www.theatlantic.com/ ideas/archive/2018/09/the-new-they/568993/

Pennebaker, J. W. (2013). The secret life of pronouns: What our words say about us. Bloomsbury Press.

Pilkington, O. A. (2019). Uhura and linguistics of Star Trek. In M. W. Kapell \& A. G. Pilkington (Eds.), Kelvin Timeline. McFarland \& Company, Inc.

Reiff, R. H. (2010). Choosing Thou or You to Reveal Ideal Relationships in "The Knight's Tale.” Essays in Medieval Studies, 26(1), 69-84. https://doi.org/10.1353/ems.2010.0009

Shakespeare, W. (2016). Othello. In X. J. Kennedy \& D. Gioia (Eds.), Backpack Literature (5th ed., pp. 742-852). Parson. 